\title{
Capecitabine and Vinorelbine as an All-Oral Chemotherapy in HER2-Negative Locally Advanced and Metastatic Breast Cancer
}

\author{
Simon P. Gampenrieder ${ }^{a} \quad$ Rupert Bartsch $^{\mathrm{a}} \quad$ Peter Matzneller $^{\mathrm{a}} \quad$ Ursula Pluschnig $^{\mathrm{a}}$ \\ Peter Dubsky ${ }^{\mathrm{b}}$ Michael X. Gnant ${ }^{\mathrm{b}} \quad$ Christoph C. Zielinski $^{\mathrm{a}} \quad$ Guenther G. Steger $^{\mathrm{a}}$ \\ a Universitätsklinik für Innere Medizin I, Klinische Abteilung für Onkologie,

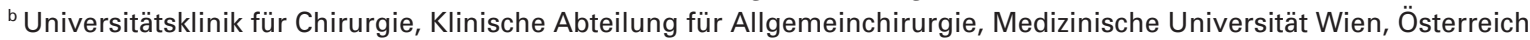

\section{Key Words}

Capecitabine - Vinorelbine - Combination therapy ·

Breast cancer, advanced

\section{Summary}

Background: The oral formulation of vinorelbine together with capecitabine allows for an all-oral combination chemotherapy which promises to raise quality of life of patients with advanced breast cancer. Patients and Methods: Patients with HER2-negative, locally advanced, inoperable or metastatic breast cancer were included in this prospective observational trial (treatment schedule: capecitabine $500 \mathrm{mg} / \mathrm{m}^{2}$ twice daily, days 1-14; vinorelbine $60 \mathrm{mg} / \mathrm{m}^{2}$, days $1+8$; repeated in 3-week cycles). Results: All 32 patients (median age 50 years) were evaluable for toxicity, and 30 patients for response. Twentyfour patients received therapy as first-line treatment, and 8 patients as beyond first-line treatment. Median time to progression was 8 months, and median overall survival was 32 months. Complete response was observed in 1 patient $(3 \%)$, partial response in 10 patients $(33 \%)$, and disease stabilization for more than 6 months $(S D>6)$ in 10 patients $(33 \%)$. This results in an overall response rate (ORR) of $37 \%$ and a clinical benefit rate (ORR $+S D>6$ ) of $70 \%$. The only grade $3 / 4$ toxicities were neutropenia $(19 \%)$ and hand-foot syndrome (9\%). Conclusions: The all-oral combination of capecitabine/vinorelbine at this schedule appears to be an effective, well-tolerated regimen for treatment of advanced breast cancer, and offers a promising alternative to single-agent capecitabine and vinorelbine as well as intravenous polychemotherapy.

\author{
Schlüsselwörter \\ Capecitabin · Vinorelbin · Kombinationschemotherapie . \\ Mammakarzinom, fortgeschrittenes
}

\section{Zusammenfassung}

Hintergrund: Orales Vinorelbin in Kombination mit Capecitabin eröffnet die Möglichkeit eines rein oralen Therapiekonzepts beim fortgeschrittenen Mammakarzinom. Ein solches Regime ist einfach und bequem durchführbar und könnte die Akzeptanz der Therapie steigern. Patienten und Methoden: Patientinnen mit HER2-negativem, lokal fortgeschrittenem oder metastasiertem Brustkrebs wurden in diese prospektive Beobachtungsstudie eingeschlossen (Behandlungsschema: Capecitabin $500 \mathrm{mg} / \mathrm{m}^{2}$ zweimal täglich, d1-14; Vinorelbin $60 \mathrm{mg} / \mathrm{m}^{2}$, d1+8, Wiederholung d22). Ergebnisse: 32 Patientinnen (medianes Alter 50 Jahre) standen für die Bewertung der Toxizität, 30 für die Evaluation des Ansprechens zur Verfügung. Die mediane Zeit bis zum Fortschreiten der Erkrankung betrug 8 Monate, das mediane Gesamtüberleben 32 Monate. Eine komplette Remission wurde bei 1 Patientin (3\%), eine partielle Remission bei 10 Patientinnen (33\%) und eine stabile Erkrankung für $>6$ Monate $(\mathrm{SD}>6)$ bei 10 Patientinnen (33\%) beobachtet. Die Ansprechrate (ORR) lag somit bei $37 \%$ und die CBR (clincal benefit rate $=\mathrm{ORR}+\mathrm{SD}>6$ ) bei $70 \%$. Die einzigen Grad-3/4-Toxizitäten waren Neutropenie (19\%) und HandFuß-Syndrom (9\%). Schlussfolgerungen: Die orale Kombinationstherapie bestehend aus Vinorelbin und Capecitabin bietet eine wirksame, gute verträgliche und bequem zu verabreichende Therapieoption für Patientinnen mit fortgeschrittenem Brustkrebs. Sie stellt eine vielversprechende Alternative zur Monotherapie mit den Einzelsubstanzen und zu intravenöser Chemotherapie dar.

\begin{tabular}{ll}
\hline KARGER & @ 2010 S. Karger GmbH, Freiburg \\
Fax +497614520714 & Accessible online at: \\
Information@Karger.de & www.karger.com/brc \\
www.karger.com &
\end{tabular}




\section{Introduction}

Breast cancer remains the most frequent cause of cancer death among women [1], and metastatic breast cancer (MBC), while sensitive to chemotherapy, is still incurable. Therefore, quality of life (QoL) issues are of major importance. An oral chemotherapy essentially contributes to QoL by reducing the impact on daily activities: while patients spend a lot of time traveling to, waiting for, and receiving intravenous chemotherapy, oral chemotherapy can be administered at home. In addition, oral cytotoxic drugs are cost-saving [2].

Capecitabine, an oral fluoropyrimidine, shows significant efficacy both as a single agent and in combination, and has emerged as a valuable treatment option in MBC [3-5]. Vinorelbine is a semi-synthetic vinca alkaloid and yields first-line overall response rates (ORR) of 35-59\% in MBC [6-8]. Also, the activity of the oral formulation has been assessed in several trials, with time to progression (TTP) in the range of 4-6 months and ORR of 24-31\% [9-12]. Preclinical data suggested synergistic activity of capecitabine and vinorelbine [13]. A series of phase II studies investigated the combination of intravenous vinorelbine and capecitabine in chemotherapy-naive and heavily pretreated $\mathrm{MBC}$, showing promising results (ORR 49-70\%) and manageable toxicity [14-16]. Two phase I studies with an all-oral combination of vinorelbine and capecitabine recommended a dosage of capecitabine $2,000 \mathrm{mg} / \mathrm{m}^{2}$ and vinorelbine $60 \mathrm{mg} / \mathrm{m}^{2}[17,18]$. Based upon those data, several phase II studies were initiated [19-23]. Here, we present the results of a prospective observational trial investigating the activity and safety of an all-oral combination chemotherapy of vinorelbine (Navelbine oral ${ }^{\circledR}$, Pierre Fabre Pharma, Freiburg, Germany) and capecitabine (Xeloda ${ }^{\circledR}$, Roche Pharma AG, Grenzach-Wyhlen, Germany) in HER2-negative, locally advanced, inoperable or metastatic breast cancer.

\section{Patients and Methods}

All data were collected at the Department of Medicine I, Clinical Division of Oncology, Medical University of Vienna, Austria. All patients gave written informed consent, and treatment conformed to the ethical regulations of the Medical University of Vienna.

\section{Eligibility}

Criteria for inclusion were as follows: histologically confirmed HER2-negative, locally advanced, inoperable or metastatic breast cancer with measurable or immeasurable disease; performance status $0-1$ on ECOG (Eastern Cooperative Oncology Group) scale, predicted life expectancy > 3 months; adequate baseline hematological parameters (white blood cell (WBC) count $\geq 3,500 / \mu$, platelet count $\geq 100,000 / \mu \mathrm{l}$, hemoglobin levels $>9 \mathrm{~g} / \mathrm{dl}$ ) and organ functions (serum bilirubin $<1.5 \mathrm{mg} / \mathrm{dl}$, serum creatinine $<1.5 \mathrm{mg} / \mathrm{dl}$, left ventricular ejection fraction $(\mathrm{LVEF})>55 \%$ ). Prior adjuvant or palliative treatments with cytotoxic or endocrine drugs were allowed.

\section{Pretreatment Evaluation}

Confirmation of metastatic disease was achieved by computed tomography (CT) scans of the chest and abdomen and mammography, with fur-
Table 1. Patient characteristics $(n=32)$

\begin{tabular}{|c|c|}
\hline ECOG performance score $0-1, \mathrm{n}(\%)$ & $32(100)$ \\
\hline Age at diagnosis, median (range), years & $50(32-70)$ \\
\hline \multicolumn{2}{|l|}{ Stage at diagnosis, $\mathrm{n}(\%)$} \\
\hline I & $1(3.1)$ \\
\hline II & $10(31.3)$ \\
\hline III & $12(37.5)$ \\
\hline IV & $8(25.0)$ \\
\hline n.a. & $1(3.1)$ \\
\hline \multicolumn{2}{|l|}{ Grading, n (\%) } \\
\hline 1 & $2(6.3)$ \\
\hline 2 & $14(43.8)$ \\
\hline 3 & $14(43.8)$ \\
\hline n.a. & $2(6.3)$ \\
\hline \multicolumn{2}{|l|}{ Histology, n (\%) } \\
\hline Ductal & $21(65.6)$ \\
\hline Lobular & $10(31.3)$ \\
\hline n.a. & $1(3.1)$ \\
\hline \multicolumn{2}{|l|}{ Hormone receptor status, n (\%) } \\
\hline Estrogen receptor-positive & $23(71.9)$ \\
\hline Progesterone receptor-positive & $14(43.8)$ \\
\hline \multicolumn{2}{|l|}{ HER2 status (IHC/FISH), n (\%) } \\
\hline HER2++ / FISH- & $4(12.5)$ \\
\hline HER2+ & $6(18.8)$ \\
\hline HER2- & $22(68.8)$ \\
\hline \multicolumn{2}{|l|}{ Prior endocrine therapy, n (\%) } \\
\hline Adjuvant & $13(40.6)$ \\
\hline Palliative & $16(50.0)$ \\
\hline \multicolumn{2}{|l|}{ Prior chemotherapy, n (\%) } \\
\hline Neoadjuvant/adjuvant & $19(59.4)$ \\
\hline Palliative & $8(25.0)$ \\
\hline Anthracycline & $17(53.1)$ \\
\hline Taxane & $11(34.4)$ \\
\hline Time to recurrence, median (range), months & $59(15-180)$ \\
\hline \multicolumn{2}{|l|}{ Treatment line, $\mathrm{n}(\%)$} \\
\hline First-line & $24(75.0)$ \\
\hline Second-line & $7(21.9)$ \\
\hline Third-line & $1(3.1)$ \\
\hline Number of metastatic sites, median (range), $\mathrm{n}$ & $2(0-4)$ \\
\hline More than one metastatic site, $\mathrm{n}(\%)$ & $19(59.4)$ \\
\hline \multicolumn{2}{|l|}{ Metastatic sites, $\mathrm{n}(\%)$} \\
\hline Locally advanced inoperable & $1(3.3)$ \\
\hline Visceral (v) only & $3(9.4)$ \\
\hline Non-visceral (nv) only & $17(53.1)$ \\
\hline Bones only & $8(25.0)$ \\
\hline Visceral and non-visceral & $11(34.4)$ \\
\hline \multicolumn{2}{|l|}{ Location of metastasis, n (\%) } \\
\hline Bones (nv) & $23(71.9)$ \\
\hline Soft tissue (nv) & $10(31.3)$ \\
\hline Lung (v) & $8(25.0)$ \\
\hline Liver (v) & $7(21.9)$ \\
\hline Lymph nodes (nv) & $6(18.8)$ \\
\hline Local recurrence (nv) & $3(9.4)$ \\
\hline $\operatorname{Brain}(\mathrm{v})$ & $0(0.0)$ \\
\hline Other (v) & $3(9.4)$ \\
\hline
\end{tabular}

ECOG = Eastern Cooperative Oncology Group; n.a. = not available; HER2 = human epidermal growth factor receptor 2;

$\mathrm{IHC}=$ immunohistochemistry; FISH = fluorescence in situ hybridization; $\mathrm{v}=$ visceral $; \mathrm{nv}=$ non-visceral 
ther work up if indicated. HER2 status was assessed by immunohistochemistry (Herceptest ${ }^{\boxplus}$, Dako A/S, Glostrup, Denmark) or dual color fluorescence in situ hybridization (FISH; PathVision ${ }^{\circledR}$ HER2 DNA probe kit, Vysis Inc., Downers Grove, IL, USA). Tumors were classified as HER2-negative if either the Herceptest was negative/1+ or FISH analysis showed no gene amplification.

\section{Treatment Schedule}

Each 3-week cycle consisted of $500 \mathrm{mg} / \mathrm{m}^{2}$ capecitabine twice daily ( 2 weeks on, 1 week off), and $60 \mathrm{mg} / \mathrm{m}^{2}$ oral vinorelbine on days 1 and 8 . The vinorelbine dose was rounded to a multiple of 10 . Treatment was conducted in an outpatient setting. Patients received a diary for daily documentation of medication intake and adverse events. Treatment was continued unless disease progressed or intolerable toxicities occurred. In the case of obvious non-compliance or patient refusal, treatment was discontinued as well.

\section{Follow-Up Evaluation}

Complete blood cell count and differential WBC count were performed on days 1,8 , and 15 of the first cycle; if no grade III/IV neutropenia was observed, a single test previous to the following cycle was done. For each cycle, toxicities were graduated according to the Common Terminology Criteria for Adverse Events v3.0 (CTCEA), and the worst episode was

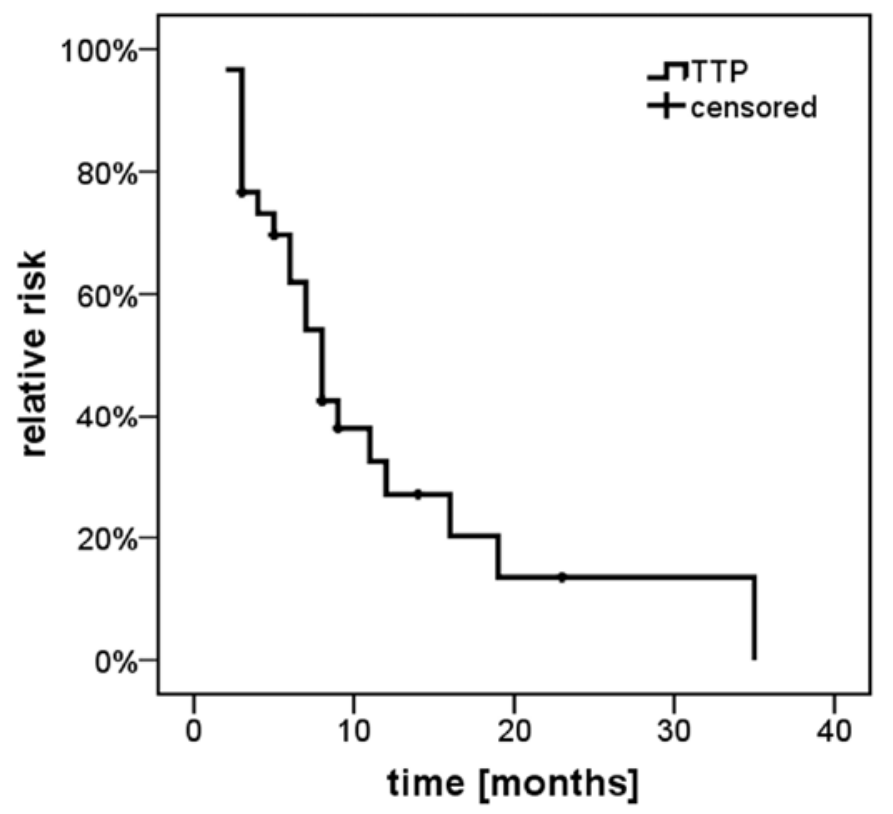

Fig. 1. Time to progression $(\mathrm{TTP})$ in months $(\mathrm{n}=30)$. Events: $22(73 \%)$, censored: 8 (27\%), median time: 8.0 months. reported. Compliance was evaluated by patient diary and counting of remaining tablets. Dose modifications were performed if toxicities grade II/III occurred: at the first appearance, treatment was delayed for 1 week or until toxicity resolved to grade I or better. In the case of reappearance or grade III toxicity, treatment was interrupted and the dose of either one or both drugs reduced to $75 \%$, ultimately to $50 \%$ of the original dose, and maintained during all next cycles. The use of granulocyte colony-stimulating factor (G-CSF) was permitted.

\section{Response Evaluation}

According to the UICC guidelines, tumor response was assessed every 3 cycles. Additional staging was performed at any time if clinical symptoms of disease progression emerged. The best achieved overall response for each patient, classified using standard UICC criteria, was reported.

\section{Statistical Analysis}

The primary endpoint was TTP. ORR, clinical benefit rate (CBR), tolerability, and overall survival (OS) were defined as secondary endpoints. TTP and OS were estimated by the Kaplan-Meier method. Differences between TTP curves were evaluated using the log-rank test. All statistics were calculated using SPSS version 16.0 (SPSS Inc, Chicago, IL, USA).

\section{Results}

\section{Patient Characteristics}

Between March 2004 and June 2008, 32 patients (median age 50 years, range 32-70) with locally advanced, inoperable or metastatic breast cancer were entered as eligible for capecitabine/vinorelbine treatment. All patients received at least 1 cycle of the study medication and were included in the intention-to-treat analysis of toxicity. Of those, 30 patients are evaluable for response. One patient was excluded from the evaluation because of insufficient compliance; the other patient withdrew her consent prior to the first tumor evaluation. Detailed characteristics of all 32 patients are shown in table 1.

\section{Response}

Median time of observation was 13 months (range 3-53). Median TTP was 8 months (range $2-35,95 \%$ confidence interval (CI) 7.25-16.12) (fig. 1). The log-rank test revealed no significant differences between the TTP curves for first-line (24 patients) and beyond first-line treatment ( 6 patients). Median OS was 32 months (range 5-53, 95\% CI 24.46-41.55). Efficacy data are summarized in table 2.
Table 2. Response rates $(\mathrm{n}=30)$

\begin{tabular}{llrrrrrr}
\hline \multicolumn{7}{l}{ Response, $\mathrm{n}(\%)^{\mathrm{a}}$} \\
\cline { 2 - 8 } & CR & \multicolumn{1}{c}{ PR } & ORR & \multicolumn{1}{c}{ SD $\geq 6$} & \multicolumn{1}{c}{ CBR } & SD $<6$ & PD \\
\hline Overall $(\mathrm{n}=30)$ & $1(3.3)$ & $10(33.3)$ & $11(36.7)$ & $10(33.3)$ & $21(70.0)$ & $1(3.3)$ & $8(26.7)$ \\
First-line $(\mathrm{n}=24)$ & $1(4.2)$ & $7(29.2)$ & $8(33.3)$ & $8(33.3)$ & $16(66.7)$ & $1(4.2)$ & $7(29.2)$ \\
Beyond first-line $(\mathrm{n}=6)$ & $-(-)$ & $3(50.0)$ & $3(50.0)$ & $2(33.3)$ & $5(83.3)$ & \multicolumn{1}{c}{$-(-)$} & $1(16.7)$ \\
\hline
\end{tabular}

${ }^{\mathrm{a} A c c o r d i n g}$ to UICC criteria.

$\mathrm{CR}=$ Complete response; $\mathrm{PR}=$ partial response; $\mathrm{ORR}=$ overall response rate $(\mathrm{CR}+\mathrm{PR})$;

$\mathrm{SD} \geq 6$ = stable disease lasting at least 6 months; $\mathrm{CBR}=$ clinical benefit rate $(\mathrm{ORR}+\mathrm{SD} \geq 6) ; \mathrm{SD}<6=$ stable disease lasting less than 6 months; PD = progressive disease. 


\begin{tabular}{llrlll}
\hline Toxicity & \multicolumn{4}{l}{ Grade, $\mathrm{n}(\%)^{\mathrm{a}}$} \\
\cline { 2 - 6 } & all & \multicolumn{1}{ll}{ I } & II & III & IV \\
\hline Anemia & $22(68.8)$ & $16(50.0)$ & $6(18.8)$ & $-(-)$ & $-(-)$ \\
Neutropenia & $19(59.4)$ & $5(15.6)$ & $8(25.0)$ & $4(12.5)$ & $2(6.3)$ \\
Thrombocytopenia & $10(31.3)$ & $10(31.3)$ & $-(-)$ & $-(-)$ & $-(-)$ \\
Nausea & $17(53.1)$ & $8(25.0)$ & $9(28.1)$ & $-(-)$ & $-(-)$ \\
Vomiting & $13(40.6)$ & $8(25.0)$ & $5(15.6)$ & $-(-)$ & $-(-)$ \\
Diarrhea & $13(40.6)$ & $12(37.5)$ & $1(3.1)$ & $-(-)$ & $-(-)$ \\
Fatigue & $12(37.5)$ & $8(25.0)$ & $4(12.5)$ & $-(-)$ & $-(-)$ \\
Hand-foot syndrome & $11(34.4)$ & $3(9.4)$ & $5(15.6)$ & $3(9.4)$ & \\
Polyneuropathia & $4(12.5)$ & $3(9.4)$ & $1(3.1)$ & $-(-)$ & $-(-)$ \\
Stomatitis & $2(6.3)$ & $2(6.3)$ & $-(-)$ & $-(-)$ & $-(-)$ \\
Alopecia & $2(6.3)$ & $2(6.3)$ & $-(-)$ & & \\
\hline
\end{tabular}

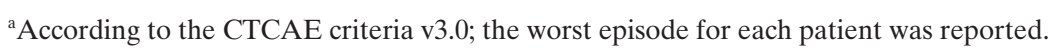

\section{Toxicity}

The total number of cycles administered was 331, with a median of 8 cycles per patient (range 1-47). Toxicities are summarized in table 3 . Neutropenia grade IV was observed in 2 patients $(6 \%)$, while 4 patients $(13 \%)$ suffered from neutropenia grade III. One patient with neutropenia grade IV developed neutropenic fever and had to be admitted to hospital. Only 3 cases $(9 \%)$ of grade III hand-foot syndrome were observed. Nausea and vomiting, toxicities important for compliance with an all-oral regimen, were seen frequently (53 and $41 \%$, respectively), yet only 3 patients (9\%) discontinued treatment because of nausea grade II. Two patients experienced arterial occlusion (posterior tibial artery and common iliac artery, respectively), and 1 patient a pulmonary embolism while on treatment. In 17 patients $(53 \%)$, treatment was delayed for at least 1 week. In 5 patients $(16 \%)$, the dose of both drugs was reduced to $75 \%$, in 6 patients $(19 \%)$ only the dose of capecitabine was reduced.

\section{Discussion}

Considering the putative synergistic effect of vinorelbine and capecitabine, a combination of those agents might result in enhanced anti-tumor activity. This study, while suggesting high clinical activity, is limited by the relatively small number of patients and the fact that $53 \%$ presented with non-visceral metastases only. The low median age may be explained by the fact that investigators will often regard healthy patients as ideal candidates for combination chemotherapy. Therefore, our data require confirmation in larger controlled trials.

Regarding efficacy, this regimen appears active with 8 months TTP and $36.7 \%$ ORR. For capecitabine as first-line monotherapy, TTP of 3-4.1 months and response rates of 30$36 \%$ were reported $[4,24]$. Intravenous vinorelbine as firstline treatment yielded 5.8 months TTP and $41 \%$ ORR [6]. In pretreated patients, Gasparini et al. [25] reported 4.5 months TTP and 36\% ORR. Similar efficacy results were obtained in a phase II study of oral vinorelbine [11]. Our results, on the other hand, compare well to data of intravenous as well as oral vinorelbine in combination with capecitabine (TTP 7.610.5 months) [15, 16, 22, 23, 26], suggesting superior efficacy over the respective single agents.

Side effects were predictable. The relatively low hematological toxicity (only 1 patient developed neutropenic fever) is probably caused by the low dose of vinorelbine. Although hand-foot syndrome and gastrointestinal toxicities were common, influence on compliance was low due to dose reduction (dosage of capecitabine and vinorelbine was reduced in 35 and $16 \%$, respectively). Three cardiovascular incidents (arterial occlusions and pulmonary embolism) occurring during the study period were not thought to be associated with the study drugs; interestingly, Nolè et al. [23] also reported 5 cases of thrombosis. When compared to toxicity profiles of singleagent capecitabine and vinorelbine [27], our regimen showed a far better profile in almost all categories, probably due to lower doses of both drugs. As for the combination of capecitabine and intravenous vinorelbine, results reported by Welt et al. [15] compare well to our data. Two other studies, in contrast, reported a far better toxicity profile $[14,16]$. Concerning capecitabine/oral vinorelbine, Nolè et al. [23] reported a higher incidence of neutropenia grade III/IV (47\%), diarrhea $(67 \%)$, and stomatitis $(40 \%)$, and a similar percentage of hand-foot syndrome (37\%). Of note, a third dosage of $60 \mathrm{mg} /$ $\mathrm{m}^{2}$ vinorelbine on day 15 was administered, probably causing the higher toxicity and study discontinuation rate (19\%). In contrast, Finek et al. [22] demonstrated a very low number of grade III/IV side effects. In sum, side effects were manageable, and this combination appears superior to other combination treatments in terms of toxicity.

Allowing for treatment in an outpatient setting, an all-oral chemotherapy essentially contributes to QoL [2]. Compliance was considered good. Overdosing was not a relevant problem; however, 1 patient had to be excluded from the evaluation because of overdosing vinorelbine, resulting in severe toxicities. 


\section{Conclusion}

In summary, our results indicate that capecitabine and oral vinorelbine is a reasonably well tolerated and active treatment option in advanced breast cancer. To confirm those results, larger controlled clinical trials are warranted. Fit patients with anthracycline and taxane pretreatment might be candidates for this regimen.

\section{Conflict of Interest}

R. Bartsch has received lecture honoraria from Roche (Xeloda) and Pierre Fabre (Navelbine). M. Gnant has received lecture honoraria and research support from Roche. C.C. Zielinski has received speaker's fees and honoraria for participation in advisory boards from Roche. G.G. Steger has received speaker's fees from Boehringer Ingelheim (Navelbine) and speaker's fees, honoraria for participation in advisory boards, and research support from Roche. All other authors declared no conflict of interest.

\section{References}

1 Jemal A, Siegel R, Ward E, Hao Y, Xu J, Murray T, Thun MJ: Cancer statistics, 2008. CA Cancer J Clin 2008;58:71-96.

2 Findlay M, von Minckwitz G, Wardley A: Effective oral chemotherapy for breast cancer: pillars of strength. Ann Oncol 2008;19:212-222.

3 Blum JL, Dieras V, Lo Russo PM, Horton J, Rutman O, Buzdar A, Osterwalder B: Multicenter, phase II study of capecitabine in taxane-pretreated metastatic breast carcinoma patients. Cancer 2001; 92:1759-1768.

4 Talbot DC, Moiseyenko V, Van Belle S, O'Reilly SM, Alba Conejo E, Ackland S, Eisenberg P, Melnychuk D, Pienkowski T, Burger HU, Laws S, Osterwalder B: Randomised, phase II trial comparing oral capecitabine (xeloda) with paclitaxel in patients with metastatic/advanced breast cancer pretreated with anthracyclines. Br J Cancer 2002;86: $1367-1372$

5 O'Shaughnessy JA, Blum J, Moiseyenko V, Jones SE, Miles D, Bell D, Rosso R, Mauriac L, Osterwalder B, Burger HU, Laws S: Randomized, openlabel, phase II trial of oral capecitabine (xeloda) vs. a reference arm of intravenous CMF (cyclophosphamide, methotrexate and 5-fluorouracil) as firstline therapy for advanced/metastatic breast cancer. Ann Oncol 2001;12:1247-1254.

6 Fumoleau P, Delgado FM, Delozier T, Monnier A, Gil Delgado MA, Kerbrat P, Garcia-Giralt E, Keiling R, Namer M, Closon MT, et al.: Phase II trial of weekly intravenous vinorelbine in first-line advanced breast cancer chemotherapy. J Clin Oncol 1993;11:1245-1252.

7 Weber BL, Vogel C, Jones S, Harvey H, Hutchins L, Bigley J, Hohneker J: Intravenous vinorelbine as first-line and second-line therapy in advanced breast cancer. J Clin Oncol 1995;13:2722-2730.

$\checkmark 8$ Terenziani M, Demicheli R, Brambilla C, Ferrari L, Moliterni A, Zambetti M, Caraceni A, Martini C, Bonadonna G: Vinorelbine: an active, non crossresistant drug in advanced breast cancer. Results from a phase II study. Breast Cancer Res Treat 1996;39:285-291.

9 Bartsch R, Wenzel C, Pluschnig U, Hussian D, Sevelda U, Locker GJ, Mader R, Zielinski CC, Steger GG: Oral vinorelbine alone or in combination with trastuzumab in advanced breast cancer: results from a pilot trial. Cancer Chemother Pharmacol 2006;57:554-558.
10 Baweja M, Suman VJ, Fitch TR, Mailliard JA, Bernath A, Rowland KM, Alberts SR, Kaur JS, Perez EA: Phase II trial of oral vinorelbine for the treatment of metastatic breast cancer in patients > or $=65$ years of age: an NCCTG study. Ann Oncol 2006;17:623-629.

11 Freyer G, Delozier T, Lichinister M, Gedouin D, Bougnoux P, His P, Imadalou K, Trillet-Lenoir V: Phase II study of oral vinorelbine in first-line advanced breast cancer chemotherapy. J Clin Oncol 2003;21:35-40.

12 Winer EP, Chu L, Spicer DV: Oral vinorelbine (navelbine) in the treatment of advanced breast cancer. Semin Oncol 1995;22:72-78; discussion 78-79.

13 Sawada N, Fujimoto-Ouchi K, Ishikawa T: Antitumor activity of combination therapy with capecitabine plus vinorelbine, and capecitabine plus gemcitabine in human tumor xenograft models. Proc Am Assoc Cancer Res 2002;21:(abstr 5388)

14 Ghosn M, Kattan J, Farhat F, Younes F, Gasmi J: Phase II trial of capecitabine and vinorelbine as first-line chemotherapy for metastatic breast cancer patients. Anticancer Res 2006;26:2451-2456.

15 Welt A, von Minckwitz G, Oberhoff C, Borquez D, Schleucher R, Loibl S, Harstrick A, Kaufmann M, Seeber S, Vanhoefer U: Phase I/II study of capecitabine and vinorelbine in pretreated patients with metastatic breast cancer. Ann Oncol 2005;16:64-69.

16 Estevez LG, Batista N, Sanchez-Rovira P, Velasco A, Provencio M, Leon A, Domine M, Cruz J, Rodriguez M: A phase II study of capecitabine and vinorelbine in patients with metastatic breast cancer pretreated with anthracyclines and taxanes. Clin Breast Cancer 2008;8:149-154.

17 Kellokumpu-Lehtinen PL, Sunela K, Lehtinen I, Joensuu H, Sjostrom-Mattson J: A phase I study of an all-oral combination of vinorelbine/capecitabine in patients with metastatic breast cancer previously treated with anthracyclines and/or taxanes. Clin Breast Cancer 2006;7:401-405.

18 Nole F, Catania C, Sanna G, Imadalou K, Munzone E, Adamoli L, Longerey B, Blanchot G, Goldhirsch A: Dose-finding and pharmacokinetic study of an all-oral combination regimen of oral vinorelbine and capecitabine for patients with metastatic breast cancer. Ann Oncol 2006;17:322-329.

19 Delcambre C, Veyret C, Levy C, Switsers O: A phase I/II study of capecitabine (x) combined with oral vinorelbine (n) as first- or second-line chemotherapy in patients (pts) with locally advanced breast cancer $(\mathrm{MBC})$. Breast Cancer Res Treat 2005;24:67(abstr 1081).
20 Lorusso V, Spada M, Giampaglia M, Misino A Calabrese R, Latorre A, Monticelli G, Guida M, Sambiasi D, Colucci G: Oral vinorelbine plus capecitabine (oral vincap) combination in patients with advanced breast cancer (ABC). A phase II study of the GOIM (gruppo oncologico dell'italia meridionale). Ann Oncol 2006;17(suppl 7):vii15-17.

21 Tubiana-Mathieu N, Bougnoux P, Becquart D, Chan A, Majois F: Phase II study of an alloral combination of oral vinorelbine (nvbo) and capecitabine ( $\mathrm{x}$ ) in HER2-negative metastatic breast cancer (MBC): first results of an international phase II trial. Breast Cancer Res Treat 2006; 100:280(abstr 6072).

22 Finek J, Holubec L, Jr., Svoboda T, Sefrhansova L, Pavlikova I, Votavova M, Sediva M, Filip S, Kozevnikova R, Kormunda S: A phase II trial of oral vinorelbine and capecitabine in anthracycline pretreated patients with metastatic breast cancer. Anticancer Res 2009;29:667-670.

23 Nole F, Crivellari D, Mattioli R, Pinotti G, Foa P, Verri E, Fougeray R, Brandely M, Goldhirsch A: Phase II study of an all-oral combination of vinorelbine with capecitabine in patients with metastatic breast cancer. Cancer Chemother Pharmacol 2009;64:673-680.

24 Oshaughnessy JA, Blum J, Moiseyenko V, Jones SE, Miles D, Bell D, Rosso R, Mauriac L, Osterwalder B, Burger HU, Laws S: Randomized, openlabel, phase II trial of oral capecitabine (xeloda) vs. a reference arm of intravenous CMF (cyclophosphamide, methotrexate and 5-fluorouracil) as firstline therapy for advanced/metastatic breast cancer. Ann Oncol 2001;12:1247-1254.

25 Gasparini G, Caffo O, Barni S, Frontini L, Testolin A, Guglielmi RB, Ambrosini G: Vinorelbine is an active antiproliferative agent in pretreated advanced breast cancer patients: a phase II study. J Clin Oncol 1994;12:2094-2101.

26 Ghosn M, Kattan J, Farhat F, Younes F, Nasr F, Moukadem W, Gasmi J, Chahine G: Sequential vinorelbine-capecitabine followed by docetaxel in advanced breast cancer: long-term results of a pilot phase II trial. Cancer Chemother Pharmacol 2008; 62:11-18.

27 Mano M: Vinorelbine in the management of breast cancer: New perspectives, revived role in the era of targeted therapy. Cancer Treat Rev 2006;32:106118. 